\title{
Implementation of a Socio-structural Demonstration Project to Improve HIV Outcomes Among Young Black Men in the Deep South
}

\author{
Russell Brewer, $\mathrm{DrPH}^{1}$ (D) C Chris Daunis, $\mathrm{MSAS}^{2} \cdot$ Sabira Ebaady, $\mathrm{MPH}^{2} \cdot$ Leo Wilton, $\mathrm{PhD}^{3,4} \cdot$ Sarah Chrestman, $\mathrm{MPH}^{2}$. \\ Snigdha Mukherjee, $\mathrm{PhD}^{5} \cdot$ Mary Moore, $\mathrm{MS}^{6} \cdot$ Renee Corrigan ${ }^{7} \cdot$ John Schneider, MD, MPH ${ }^{1}$
}

Received: 29 August 2018 / Revised: 31 January 2019 / Accepted: 12 February 2019 / Published online: 21 February 2019

(C) W. Montague Cobb-NMA Health Institute 2019

\begin{abstract}
Background We describe the background, rationale, intervention components, and formative results of a demonstration project aimed to ameliorate five socio-structural barriers to HIV services for young Black men aged 18-29 living with and at risk for HIV in Louisiana.

Methods The interventions and activities consisted of (1) five person-centered approaches to enhance linkage to HIV services and improve socio-economic outcomes; (2) the implementation of systematic mystery shopping tests to document instances of housing discrimination; (3) the development and implementation of a multi-prong communications campaign to increase knowledge about the signs of housing discrimination and community resources among young Black men who have sex with men (YBMSM); (4) the integration of HIV/STI services and lesbian, gay, bisexual, and trans (LGBT)-inclusive events on Historically Black Colleges and Universities (HBCUs); and (5) the development of a safe space for YBMSM. A multi-method approach was used to evaluate the outcomes of the different interventions.

Results The majority (62\%) of participants living with HIV were linked to HIV care and $49 \%$ had achieved viral suppression. More than $40 \%$ of participants were employed during the project. Thirty-seven percent (37\%) of the mystery shopping tests showed definite or possible signs of housing discrimination. The housing campaign's duration was limited with unknown longterm impact among YBMSM. Fifteen cases of syphilis were identified during two HBCU events. A safe space was specifically created for YBMSM at a community-based organization.

Conclusion Multi-component holistic health interventions are needed to improve HIV outcomes and curb the high HIV rates among young Black men, particularly YBMSM in the United States and the Deep South.
\end{abstract}

Keywords Black men who have sex with men (BMSM) $\cdot$ Social and structural factors $\cdot$ HIV prevention $\cdot$ South $\cdot$ Young Black men

\section{Introduction}

Young Black men, particularly young Black men who have sex with men (YBMSM), are disproportionately impacted by HIV in the United States (US) [1-8]. Studies have shown that

Russell Brewer, DrPH

rbrewer@medicine.bsd.uchicago.edu

1 Department of Medicine, University of Chicago, 5837 S. Maryland Ave., Chicago, IL 60637, USA

2 Louisiana Public Health Institute, 1515 Poydras Street, Suite 1200, New Orleans, LA 70112, USA

3 State University of New York at Binghamton, Human Development Department, University Downtown Center, 67 Washington Street, Binghamton, NY 13901-3702, USA sexual and substance-use risk behaviors do not fully account for the HIV disparities observed between YBMSM and other groups [3-7]. Instead, multiple socio-structural factors such as unstable housing, HIV stigma, limited access to HIV services, incarceration history, lack of safe spaces, and unemployment

4 Faculty of Humanities, University of Johannesburg, PO Box 524, Auckland Park 2006, Johannesburg, South Africa

5 Foundation for Advancement of International Medical Education and Research, 3624 Market Street, Philadelphia, PA 19104-2685, USA

6 Dillard University, 2601 Gentilly Boulevard, New Orleans, LA 70122, USA

7 Greater New Orleans Fair Housing Action Center, 1340 Poydras Street, Suite 710, New Orleans, LA 70112, USA 
contribute to HIV vulnerability and poor HIV care and treatment outcomes for Black men [3-16]. Despite the burden of HIV among young Black men, there is a dearth of holistic health interventions that simultaneously address the numerous and co-occurring socio-structural barriers to HIV services [12-15].

Given that the US South has the highest HIV diagnosis rate, highest death rate, and highest number of persons diagnosed with HIV [17], it is a high-priority region for HIV prevention, care, and treatment efforts focused on reducing the various socio-structural barriers to HIV services [15, 18-21]. Such initiatives are especially needed in Southern states such as Louisiana, which ranks high in the nation for new HIV and AIDS case rates [22-24]. Furthermore, recent estimates show that more than two thirds of newly diagnosed HIV infections in the state occurred among African Americans and men who have sex with men (MSM) with a disproportionate burden among YBMSM aged 18-29 [24].

In response to this crisis, holistic health interventions such as the Louisiana Integrated Center for Care, Supportive Services, and Community Health (LA ICCSSCH) were developed and implemented to improve HIV outcomes among young Black men in a region of the US characterized by pervasive HIV-related stigma, poverty, racial inequity and bias, and laws that reinforce HIV-related stigma and fear [17].

The purpose of this manuscript is to describe the background, rationale, intervention components, and formative results of this demonstration project. The LA ICCSSCH was a 3-year multi-city project aimed to ameliorate five sociostructural barriers to HIV services for young Black men, including heterosexually identified, as well as gay, bisexual, and other MSM, living with and at risk for HIV infection in two highly HIV-impacted communities [22-24]. There are limited published research and evaluation studies focused on addressing the socio-structural barriers to HIV services among young Black men in the Deep South $[15,19,21]$. In addition, there is a gap in the intervention literature connecting decreases in socio-structural barriers with improvements in HIV prevention, care, and treatment outcomes for young Black men [8].

\section{Background on Louisiana's Demonstration Project}

In 2014, the Louisiana Public Health Institute (LPHI) in New Orleans, Louisiana was one of six sites funded by the United States Department of Health and Human Services (DHHS), Office of Minority Health (OMH) in the Office of the Secretary for the HIV/AIDS Initiative for Minority Men (AIMM). AIMM was a 3-year initiative (September 2014August 2017) launched to address the unmet holistic health needs as well as improve HIV prevention, care, and treatment outcomes for young Black men aged 18-29 living with and at risk for HIV in the US [25].
Louisiana's demonstration project, the LA ICCSSCH, developed and piloted several interventions to specifically reduce socio-structural barriers to HIV prevention, treatment, and care for young Black men, especially YBMSM aged 18-29, living with and at risk for HIV infection in New Orleans and Baton Rouge. LA ICCSSCH was implemented in collaboration with 13 multi-sector partners to address the broader holistic health needs of young Black men.

\section{Overall Partnership Structure of LA ICCSSCH}

Two integrated centers composed of two groups of multisector partnerships were established in both cities to develop, implement, and evaluate coordinated strategies to improve HIV outcomes for young Black men. Integrated center partners provided client referrals to various services (e.g., HIV care, employment, legal services) within the network. The New Orleans integrated center was composed of nine partner organizations (including LPHI) while the Baton Rouge integrated center was composed of five partner organizations (including LPHI). Both integrated center partnerships consisted of primary care providers, behavioral health providers, AIDS Service Organizations, and community-based organizations which were required for the AIMM initiative. LPHI convened the integrated center partners regularly via face-to-face meetings and conference calls to plan and coordinate efforts. The integrated centers also established two city-specific community advisory boards (CABs) composed of young Black men to develop and inform program decisions and strategies. The five socio-structural priority areas as well as the reasons for their selection and intervention components are described below and summarized in Table 1.

\section{Background and Rationale for Priority Area 1 Focused on Reducing the Socio-structural Barriers to HIV Services for Criminal Justice-Involved Populations which Disproportionately Impacts Black Men, YBMSM, and Persons Living with HIV}

Louisiana has been described as the world's prison capital with more individuals, per capita, incarcerated in the state than any other place in the world [26]. An estimated 54,000 individuals are incarcerated in Louisiana's jails, prisons, and other criminal justice settings (CJS) [27]. There is an overrepresentation of African Americans in CJS given that African Americans comprise $32 \%$ of the state's population and an estimated $66 \%$ of its incarcerated population in 2010 [26, 27]. City-specific estimates also show an overrepresentation of Black men in jails as one in 14 Black men from New Orleans is behind bars [28] and Black adult men represent $28 \%$ of New Orleans' population but $80 \%$ of incarcerated individuals in the New Orleans jail [28]. 


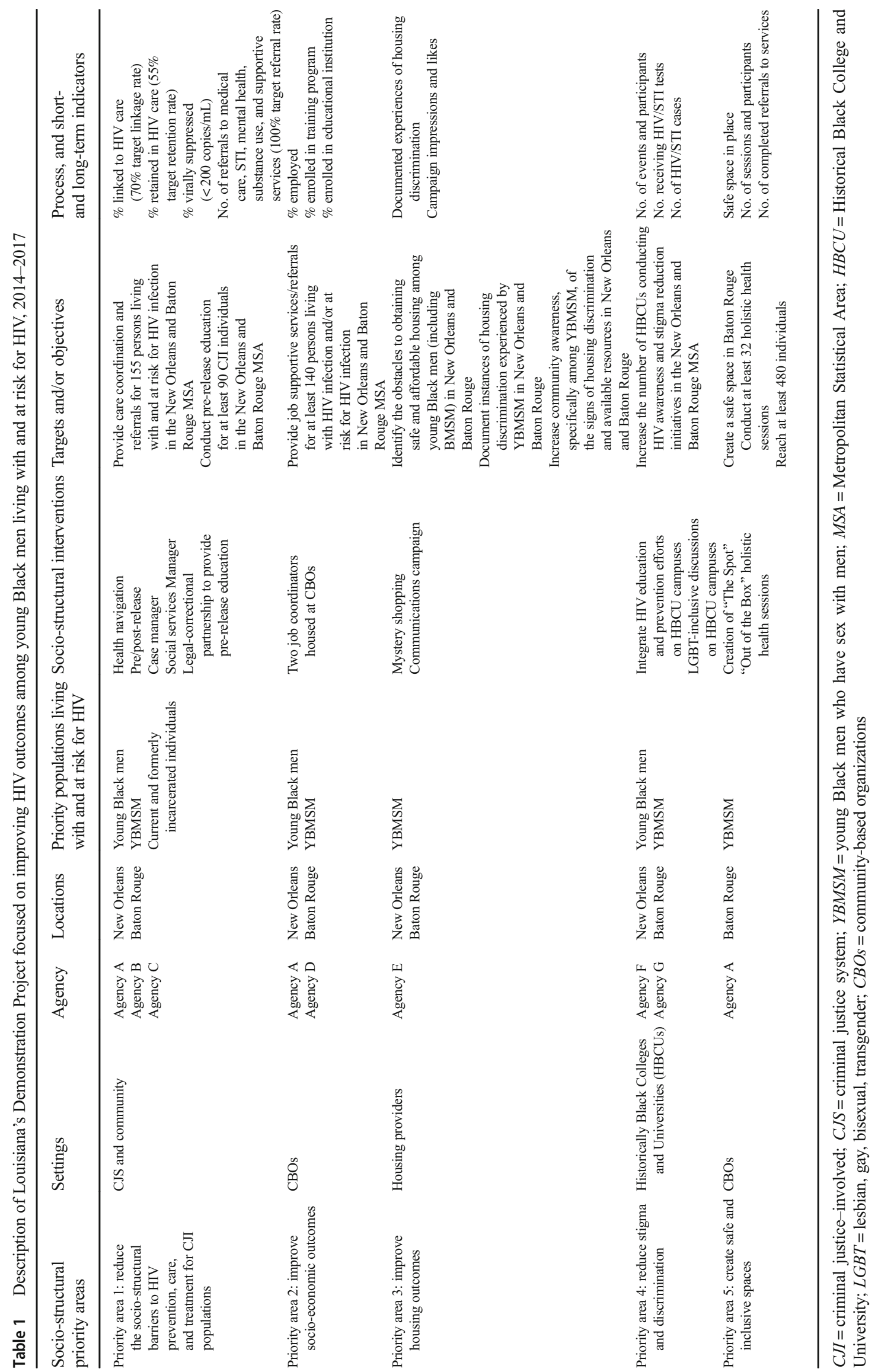


High incarceration rates have also been documented among BMSM and persons living with HIV (PLWH) in the US [29-35]. For example, a six-city study of BMSM in the US found that $60 \%$ of participating BMSM reported a prior history of incarceration [30]. It is estimated that $25 \%$ of all PLWH will enter the CJS in any given year in the US $[32,33]$ and above average general population HIV prevalence rates have been found in CJS [32, 33, 35]. Former prisoners and PLWH in Louisiana, coming out of the CJS, receive limited support for HIV care upon release [34, 36]. For example, in a Louisiana needs assessment of more than 1700 PLWH, 11\% of respondents reported being incarcerated in the past 12 months [36]. Of those with a history of incarceration, $40 \%$ reported that they did not receive referrals to medical care and case management services, HIV medications, or information about housing upon release [36]. Recently released PLWH often discontinue HIV medications as their release results in a migration from highly structured environments, in which adherence to medication might be observed and monitored into environments where access to care and adherence are often more challenging [37, 38].

In summary, improving HIV prevention, care, and treatment outcomes for criminal justice-involved (CJI) populations which disproportionately impacts Black men and PLWH was selected as a priority area for the LA ICCSSCH. Four person-centered interventions were therefore developed and implemented to address these barriers.

\section{Description of Priority Area One Interventions-Client-Centered Care Coordination (i.e., Health Navigation, Pre/Post-release Case Management, Social Services Management) and Pre-release Education for CJI Populations}

Three integrated center partners were instrumental in implementing four interventions for CJI young Black men in New Orleans and Baton Rouge (Table 1). Instead of using the actual agency names, we refer to the integrated center partners as agencies $\mathrm{A}, \mathrm{B}$, and $\mathrm{C}$, and so forth throughout the manuscript. Three of the four interventions were focused on providing client-centered care coordination (i.e., health navigation, pre/post-release case management, and social services management) for young Black men living with and at risk for HIV. Such client-centered care coordination interventions have been shown to be effective in improving linkage to HIV care among PLWH in Louisiana [19].

Agency A, located in Baton Rouge, utilized a health navigation approach where a full-time interventionist (i.e., health navigator) assisted formerly incarcerated individuals living with and at risk for HIV infection to navigate a complicated health care system (e.g., appointment reminders and accompanying clients to appointments) and provided referrals to community supportive services over a 12 -month period.
Agency B, located in New Orleans, utilized a part-time pre/ post-release case manager interventionist. This person worked with CJI medical staff to identify PLWH in a local jail, established an initial relationship with PLWH prior to release, and conducted follow-up with participants living with HIV upon release, in order to link them to medical care and supportive services over a 12-month period. Agency B also utilized a part-time social services manager interventionist to provide case management services specifically for HIVnegative clients with a history of incarceration over a 12month period. The interventionists housed at agencies A and $\mathrm{B}$ also assessed client needs and barriers at intake and 6 and 12 months to inform linkage to HIV care, primary medical care, and supportive services.

Agency C, located in New Orleans, implemented prerelease educational sessions in CJI settings. Agency $\mathrm{C}$, a legal service organization, conducted pre-release educational groups in CJI settings pertaining to community resources (e.g., signing up for Medicaid coverage, housing, employment support, and where to get medical care upon release).

\section{Background and Rationale for Priority Area 2 Focused on Improving the Socio-economic Outcomes for Young Black Men, Including YBMSM Living with and at Risk for HIV in New Orleans and Baton Rouge}

Socio-economic factors such as income, education, and employment play an important role in the US HIV epidemic [39]. HIV prevalence is highest among persons who are at or below the poverty level, who have less than a high school education, and who are unemployed in the US [39]. Several studies have also shown that these factors are significant contributors to HIV vulnerability and poor HIV outcomes for BMSM compared with other MSM in the US [5, 8-10].

Low income, unemployment, and limited education are more prevalent among Black men compared with their White counterparts in both New Orleans and Baton Rouge [40, 41]. The median earnings of Black men in New Orleans who worked full-time year-round in 2011 was $\$ 31,018$ compared with $\$ 60,075$ for White men [40]. In 2011, 12\% of Black men were unemployed in New Orleans compared with $4 \%$ of White men. A more comprehensive estimate of labor market conditions, nonemployment (i.e., individuals who are unemployed and not in the labor force to include incarcerated populations), showed that $52 \%$ of Black men in New Orleans that same year were considered non-employed compared with only $25 \%$ of White men [40]. With lower median wages and lower labor force participation rates, a greater percentage of Black men in New Orleans live in poverty (27\%) than their White male counterparts (15\%) [37]. Even though high school graduation rates among Black men in New 
Orleans have significantly increased from $45 \%$ in 1980 to $73 \%$ in 2009-2011, a high school diploma is not enough to compete in today's labor market, where the largest percentage of Black men (14\%) are employed in the accommodation and food service industry [40].

Similar racial disparities in socio-economic outcomes are observed in Baton Rouge. The Black male household income ratio in Baton Rouge for every dollar spent compared with their White male counterparts in 2011 was \$.58 [41]. Recent unemployment estimates show that the unemployment rate for young men of color was $8.14 \%$ compared with $0.4 \%$ for White men in Baton Rouge [41]. Education estimates from the most populated parish (i.e., county) in Baton Rouge also showed that less than $50 \%$ of African American males graduated high school in 2011-2012 [41]. Job coordinators were therefore utilized to improve socio-economic outcomes for young Black men including YBMSM.

\section{Description of Priority Area 2 Intervention-Utilization of Job Coordinators}

Building on client-centered care coordination interventions that have been shown to be effective in improving HIV outcomes among PLWH [19], two full-time job coordinators were hired at agency $\mathrm{D}$, a community health center in the New Orleans area, and agency A, a community-based organization in Baton Rouge to specifically provide job support services for the priority population. Job coordinators established formal and informal relationships with local employers to help support the hiring of young Black men. They also connected young Black men to existing employment resources (e.g., resume support, preparing for an interview, job placement), educational institutions (e.g., community colleges, Historically Black Colleges and Universities [HBCUs]), and specialized training programs (e.g., contractor certification). The job coordinators conducted an initial assessment of client needs and barriers to securing employment, education, and/or additional training at baseline, 6, and 12 months. The job coordinators developed an individualized plan in collaboration with each participant to address their needs and barriers.

\section{Background and Rationale for Priority Area 3 Focused on Improving Housing Outcomes for YBMSM Living with and at Risk for HIV Infection in New Orleans and Baton Rouge}

Stable housing is a necessary component of HIV prevention, care, and treatment [42]. A systematic analysis of 152 studies that were predominantly conducted in the US and Canada showed that a lack of stable housing among PLWH was a significant barrier to consistent and appropriate HIV medical care, medication access and adherence, sustained viral suppression, and increased risk of HIV transmission [42]. Persons at highest risk for HIV who lacked stable housing were also significantly more likely to acquire HIV compared with those who were stably housed [43, 44]. Housing discrimination limits the ability of racial and sexual minority populations to secure stable housing [45-47]. There are documented instances of housing discrimination by race and HIV status in Louisiana [47, 48]. A New Orleans report revealed from 50 mystery shopping audits with housing providers that African Americans, who were otherwise fully qualified, were denied the opportunity to rent or received less favorable treatment $44 \%$ of the time compared with White testers [47]. PLWH are also more likely to be discriminated against and as a result are less likely to secure adequate housing even when they can afford it [49].

Little is known about the experiences of housing discrimination among YBMSM in Louisiana. Differential treatment might include misrepresenting the availability of a unit, offering some tenants lower rent than others, being measurably less friendly to some prospective tenants, or failing to return phone calls, among other factors. Examining the impact of housing discrimination among YBMSM living with and at risk for HIV and developing interventions focused on reducing the impact of housing discrimination among this population was selected as a priority area for the LA ICCSSCH. Intervention efforts were therefore focused on documenting the impact of housing discrimination among YBMSM and developing a communications campaign to increase knowledge about the signs of housing discrimination and community resources.

\section{Description of Priority Area 3 Interventions-Documenting the Impact of Housing Discrimination Among YBMSM and Developing a Communications Campaign about the Signs of Housing Discrimination, Legal Rights to Fair Housing, and Available Resources in the Event of a Fair Housing Violation}

Agency E, a civil rights organization in New Orleans, conducted a systematic investigation of housing providers (e.g., apartment complexes) in New Orleans and Baton Rouge from October 2015 to June 2016. This approach utilized undercover mystery shoppers or testers in order to investigate the extent to which discriminatory housing practices affected YBMSM. Agency E also developed a communications campaign to educate YBMSM about the signs of housing discrimination, legal rights to fair housing, and any legal recourse available to them in the event of a fair housing violation. 


\section{Background and Rationale for Priority Area 4 Focused on Reducing Stigma and Discrimination Associated with HIV and Sexual Orientation at HBCUs}

Previous studies have documented high-risk behaviors (e.g., multiple partners, condomless sex, and drug or alcohol use during sex) among Black college students that may facilitate HIV/STI transmission and acquisition [50-52]. The current climate for sexual minority students attending HBCUs has been described as less than ideal [53]. While YBMSM have shared many positive experiences tied to attending a HBCU, such as the establishment of friendship networks and institutional pride, they have also experienced harassment, homophobia, and other stressors which are associated with HIV/STI risk behaviors [50-52, 54-56].

The majority (96\%) of HBCUs in the US are located in the South [57]. There has been some progress in creating more inclusive and stigma-free environments for sexual minority students on HBCU campuses with the presence of seven HBCUs on the Campus Pride Index [53]. Given their historic role in facilitating social change in communities of color [57], HBCUs are being challenged to address the needs of sexual minority students [58] and represent an underutilized and critical partner in addressing the stigma tied to HIV and sexual orientation given that these socio-structural factors have been shown to impede access to HIV services for many Black college students [57, 59-61]. Therefore, interventions focused on addressing stigma and creating an inclusive environment for all students, regardless of sexuality, on HBCU campuses were a priority for the LA ICCSSCH.

\section{Description of Priority Area 4 Interventions-HIV Education/Prevention Integration Efforts and Discussions Focused on Creating LGBT-Inclusive Environments on HBCU Campuses}

Pilot funds were provided to two HBCUs to support the integration of HIV education and prevention efforts and LGBTinclusive discussions on HBCU campuses.

\section{Background and Rationale for Priority Area 5 Focused on Creating Safe Spaces for YBMSM Living with and at Risk for HIV}

Prior studies have shown that BMSM experience racial discrimination from White MSM because of their race and homophobia from Black communities due to their sexual orientation [62-67]. The resulting social isolation likely contributes to feelings of alienation and other negative psychological outcomes (e.g., depression) which in turn have been associated with increased sexual risk behaviors and poor HIV outcomes [68-73].
The creation of safe and inclusive spaces at communitybased organizations (CBOs) for BMSM has been described as an important community-level approach to reduce experiences of social isolation and improve HIV prevention, care, and treatment outcomes for this population [11, 74, 75]. A study among BMSM and community stakeholders in New York City revealed that safe spaces were essential to address the underlying socio-economic impediments that were associated with HIV vulnerability and treatment incomes including institutional stigma, lack of social support, violence, housing instability, and limited educational and employment opportunities for BMSM [11].

Safe spaces have also bestowed a variety of benefits for BMSM by (1) promoting empowerment and mobilization against everyday stressors and experiences (e.g., stigma, discrimination, and violence); (2) providing educational and skills-building opportunities to those who have experienced marginalization; and (3) promoting supportive social norms and peer networks via a range of culturally relevant activities [11]. Furthermore, HIV testing and treatment campaigns were integrated within safe spaces [11]. The need to create safe spaces for YBMSM in Baton Rouge was also identified as a priority among integrated center partners in Baton Rouge. Hence, it was a major priority for the LA ICCSSCH.

\section{Description of Priority Area 5 Interventions-Creating a Safe Space in Baton Rouge for YBMSM}

A safe space called "The Spot" for YBMSM that integrated health education sessions was established at a $\mathrm{CBO}$ (i.e., agency A) in Baton Rouge.

\section{Methods}

A multi-method approach consisting of both quantitative and qualitative methods [76] was used to evaluate the multiple components of Louisiana's demonstration project. The evaluation consisted of long-term (1 year or more), short-term (less than a year), and process (activity related) measures described in Table 1. Institutional review board (IRB) approval was obtained for the study. An individual could participate in one or more interventions.

\section{Priority Area 1 Evaluation (i.e., Health Navigation, Pre/Post-release Case Management, Social Services Management, and Pre-release Education) Approach}

Upon securing informed consent, individuals receiving health navigation, pre/post-release case management, or social services management completed a baseline and follow-up ( 6 and 12 months) paper-and-pencil survey which was used to inform care coordination and referrals to supportive services. The 
surveys assessed demographic information (e.g., age, sex, sexual orientation, race, employment status, city of residence); HIV-related information (e.g., HIV testing history, HIV status); incarceration-related information (e.g., incarceration history); current needs and barriers to care; and referrals made. Participants could select more than one need at each data collection point. The interventionists (e.g., health navigator) administered the surveys in an "interview or conversation" style. Data collected on HIV negative clients were deidentified (i.e., stripped of personal information) and securely mailed to LPHI where the evaluation team completed an initial assessment for data completeness. Each individual's response was entered into an excel spreadsheet in a limited access shared drive on LPHI's server. Survey information from participants living with HIV was entered by the interventionists into CAREWare, a secure data collection system. CAREWare was shared across the intervention sites. Customized fields matching the surveys were created by the Louisiana Office of Public Health to support data entry upon client completion of a survey.

Individual-level data entered into CAREWare were transmitted through a secure portal to the Louisiana Office of Public Health. HIV clinical outcomes (e.g., viral load results) were also obtained from the Louisiana Office of Public Health to determine the number of participants living with HIV infection who had been linked to HIV care, retained in HIV care, and achieved viral suppression. Individual-level data collected via surveys for participants living with HIV infection were later matched with the surveillance data, and a participant's viral load results were extracted to form a clinical database that was de-identified and later shared with LPHI as electronic files via a secure data portal. For the evaluation of the prerelease education sessions, agency $\mathrm{C}$ documented the names and number of correctional settings, number of completed sessions, total number of participants per session, and participant demographics (i.e., race and gender) per session.

\section{Priority Area 2 (i.e., Job Coordination) Evaluation Approach}

Enrolled participants completed a baseline survey and 6- and 12-month follow-up surveys. The baseline survey captured basic demographic information; HIV-related information (e.g., HIV testing history, HIV diagnosis); employmentrelated needs; barriers to employment and employmentrelated services; and employment-related referrals made. Participants could select multiple needs at each data collection point. The baseline survey was designed to assist the interventionists (i.e., jobs coordinators) in creating individualized plans to support employment, training, and/or educational outcomes. Similar questions were asked in the subsequent follow-up surveys with the addition of whether or not referrals were accessed in the last 6 months.
The completed baseline and follow-up surveys for participants living with HIV were entered by the interventionist into CAREWare. Information collected on HIV-negative participants were de-identified and securely mailed to LPHI where the evaluation team assessed the data for completeness. Each individual's response was entered into a spreadsheet in a limited-access shared drive on LPHI's server. If a participant was diagnosed with HIV during the course of the study, his/ her data was entered into CAREWare. Similar individual-level and clinical data matching procedures already described for enrolled participants living with HIV in the job coordination intervention were completed.

\section{Priority Area 3 Evaluation Approach Focused on Housing Outcomes}

The evaluation approach for this priority area consisted of systematic audits conducted with housing providers in order to document experiences of housing discrimination among YBMSM in New Orleans and Baton Rouge. In order to ensure that the systematic audits were representative of housing practices more generally, agency E selected a wide variety of housing providers. Properties were selected in a variety of neighborhoods, including properties managed by both large housing providers and smaller mom and pop landlords, as well as properties advertised through various channels (newspapers, craigslist, and other online postings).

Housing discrimination testing often involves matched pair tests, in which one tester is a member of a protected class while the other tester is not. For the purposes of this demonstration project, tests involved multiple variables - race and sexual orientation-so a more complicated three- or fourpart testing methodology was used. In these tests, multiple testers completed each test, including a gay-identified African American tester, a heterosexual African American tester, a heterosexual White tester, and in some cases a gay White tester. In each test, the testers self-disclosed their sexual orientation (e.g., by disclosing being in a same sex partnership) to the housing provider either in person or over the phone. Testers were matched so they had similar household incomes, debts, and credit histories. Each test was designed to hold all variables constant except membership in the protected class or classes. Agency E testers were recruited from the existing $\mathrm{CABs}$ and integrated center partnership networks. All testers received standardized training, which included both classroom and field training. Testers were instructed to visit a pre-assigned property in question and to feign interest in renting an available unit. Testers generally recorded their conversations with housing providers using hidden tape recorders and submitted written reports detailing their experiences at each property. In order to minimize bias, testers were blinded to their test condition (e.g., race or sexual orientation). Once the tests were completed, agency E collected all written and 
recorded materials and analyzed them for signs of differential treatment. Both on-site and telephonic tests were conducted.

Agency E developed a communications campaign in collaboration with the established CABs to educate YBMSM about the signs of housing discrimination, legal rights to fair housing, and any legal recourse available to them in the event of a fair housing violation. The communications campaign consisted of three main modalities: print materials, bus advertisements, and social media. The campaign materials included three designs that compared looking for housing to using a dating app and were modified based on CAB recommendations. The print materials included small-size push cards with an image and campaign message on the front, and agency E's website and contact information for questions or to make a formal complaint on the back. One of the designs was also printed as a larger-size poster. In July 2017, the posters and push cards were shared with integrated center partners, other LGBT-serving organizations, clinics, bars, libraries, and community centers in both New Orleans and Baton Rouge. One of the campaign designs was adapted and sized for bus advertising, and interior cards were placed in busses in both New Orleans and Baton Rouge. In New Orleans, ads were placed in 20 Regional Transit Authority (RTA) busses and ran from July 1 to August 31, 2017.

In Baton Rouge, ads were placed in the entire fleet of 40 Capital Area Transit System (CATS) busses for 1 month (from July 31 to August 31, 2017). Two of the designs were sized and edited for Facebook, and posted to agency E's Facebook page along with a paid promotional "boost" aimed at reaching young men of color in New Orleans and Baton Rouge. Busses rotate throughout the routes, so ads would be seen by riders in all neighborhoods. We monitored the reach of the print and bus ads. The number of impressions and "likes" was monitored for the social media aspect of the communications campaign.

\section{Priority Area 4 Evaluation Focused on Reducing Stigma and Discrimination Associated with HIV and Sexual Orientation at HBCUs}

In year 3 (i.e., September 2016-August 2017) of the project, agency $\mathrm{F}$, an $\mathrm{HBCU}$, received funding to conduct HIV education and prevention efforts (e.g., HIV/STI testing) on their campus with a longer term goal of integrating and scaling up these efforts to reduce the stigma associated with HIV among students of color. Two events were held on agency F's campus. The first event was a conference that consisted of a variety of workshops designed to encourage healthy relationships. The second event was an awards celebration and fashion show. HIV/STI testing was provided during both events for college students. A second HBCU, agency G, was supported during year 3 to conduct a series of workshops over a 2-day period to support a broader dialog among student leaders, staff, and allies centered on LGBT student engagement, and holistic health, as well as strategies to create an inclusive and safe environment for all HBCU students. Process measures were collected for this priority area. They included the total number of participants, how many students received HIV/STI testing, and the number of identified HIV/STI cases.

\section{Priority Area 5 Evaluation Focused on Creating Safe Spaces for YBMSM Living with and at Risk for HIV}

Agency A in Baton Rouge identified safe space models from different cities to inform the development of a safe space for YBMSM in Baton Rouge. A safe space called "The Spot" was established in March 2017 at agency A. "The Spot" operated three times a week and consisted of a lounge area with couches and a television as well as a separate room with computers and a printer for client use. "The Spot" included a separate meeting room that could hold up to 20 individuals for educational sessions.

Holistic health education sessions called "Out of the Box" were integrated within the safe space. Consisting of 12 modules, "Out of the Box" was led by agency A's health navigator and four YBMSM who were trained to facilitate the sessions. Topics pertinent to the needs of YBMSM were discussed during each "Out of the Box" session. The choice of topics for the sessions was focused on empowering YBMSM to understand who they are, who they want to be, and how they can navigate their environments in order to achieve greater physical, mental, social, emotional, financial, and spiritual health. Participants were also encouraged to bring their friends to the next session. During the sessions, participants received information about agency A's services as well as other community resources in the area (e.g., primary medical care, preexposure prophylaxis (PrEP) services, and HIV/STI testing and treatment services). A post-session survey was created to track participation in the discussion groups. These surveys were distributed at the end of each of the "Out of the Box" sessions. Agency A also monitored the number of completed sessions.

\section{Results}

\section{Results from Priority Area 1 (i.e., Health Navigation, Pre/Post-release Case Management, Social Services Management and Pre-release Education)}

Eighty-eight (88) individuals received one of three clientcentered care coordination interventions (i.e., health navigation, pre/post-release case management, social services management) from July 2015 to April 2017. Most participants were male (84\%), Black/African American (85\%), unemployed (58\%), and living with HIV (74\%). Seventeen 
percent $(17 \%)$ were BMSM and $52 \%$ were heterosexually identified Black men. Of the 65 participants living with HIV, 40 (62\%) were linked to HIV care within 3 months; 18 (28\%) were retained in HIV care (i.e., two visits at least 90 days apart within a 12-month period); and 32 (49\%) were virally suppressed (i.e., $<200$ copies $/ \mathrm{mL}$ ) during the intervention. Agency $\mathrm{C}$ provided pre-release education for an estimated 384 individuals in three correctional facilities from June 2015 to August 2017. Most of the participants (59\%) were Black men.

\section{Results from Priority Area 2 (i.e., the Job Coordination Intervention)}

Ninety-one (91) individuals received the job coordination intervention from July 2015 to April 2017. The majority were males (81\%), Black/African American (85\%), unemployed (71\%), and living with HIV (79\%). More than a third (36\%) were BMSM and 33\% were heterosexually identified Black men. Eighty-five percent (85\%) of individuals receiving job coordination services reported that they needed full- or parttime employment at enrollment. Among those needing employment, 49\% (38) received a job referral at enrollment and $43 \%$ (33) were employed during the intervention. More than a third $(38 \%)$ of participants enrolled in the job coordination intervention indicated that they needed additional training or skills-building opportunities (e.g., job training or certification). Among those needing training, most (89\%) received a referral in this area. Finally, 10\% (3) of participants enrolled in the job coordination intervention indicated that they needed educational support (i.e., GED, college). None of these individuals received a referral in this area at enrollment.

\section{Results from the Interventions Focused on Housing Outcomes}

Out of an attempted 49 tests, agency E completed a total of 35 three-part tests. Twenty-three-part tests were completed in New Orleans and 15 were fully completed in Baton Rouge. Both systematic investigations uncovered incidents of discrimination based on race or sexual orientation (Table 2). Overall, 13 of the 35 tests (37\%) showed definite or possible signs of housing discrimination based on race or sexual orientation. In New Orleans, two tests showed discrimination based on sexual orientation, and two tests showed discrimination based on race. There were three tests where the results were inconclusive but suggested that discrimination based on race had occurred. In Baton Rouge, one test uncovered definite discrimination based on sexual orientation, while an additional two tests showed possible discrimination based on sexual orientation, and another two tests showed possible discrimination based on race. Twenty-two of the 35 tests (63\%) showed no signs of housing discrimination.
Fifteen posters and 1000 push cards were distributed during the communications campaign from July to August 2017 and reached an estimated 1750 individuals in New Orleans and Baton Rouge. Pre-determined media impressions (i.e., number of views) data assumed that each poster was seen by at least 50 people during the campaign. In terms of the bus ads, the total number of impressions for New Orleans ads was an estimated 202,000. The monthly bus ridership is 929,169 people across a fleet of 92 busses, so monthly ridership for 20 of those busses was estimated to be approximately 202,000 . This impression estimate assumes that there were no new riders for the second month. The total impressions for Baton Rouge ads were estimated to be 215,000 which is the bus system's average monthly ridership. Total New Orleans and Baton Rouge combined impressions were 417,000 . For the social media aspect of the campaign, the total number impressions for the first ad, posted August 26, 2017, were 3624, with 30 "likes" and 1 share. The total number of impressions for the second ad, posted August 28, 2017, were 2038, with 9 "likes" and 1 share. These ads reached an estimated 5662 individuals.

\section{Results from the Interventions on HBCU Campuses}

More than 2000 students participated in the HBCU events. Two hundred and forty-one (241) students were tested for HIV/STI with no new HIV cases identified and 15 identified syphilis cases.

\section{Results from the Safe Space Intervention}

From September 2015 to August 2017, the agency conducted 35 "Out of the Box" sessions. A total of 427 duplicated individuals participated in the sessions. Ninety-two percent of participants self-identified as BMSM and $79 \%$ were YBMSM. Five YBMSM participating in "Out of the Box" have also expressed an interest in becoming certified HIV testers/counselors. Agency A is working to enroll these young men in an HIV certification course with plans to develop a group of peer HIV testers who can contribute to reducing the stigma associated with HIV among their social networks and increase HIV testing among their peers and community at large.

\section{Discussion}

The purpose of this manuscript was to describe the implementation and formative results from a holistic health demonstration project focused on the broader needs of young Black men, including heterosexually identified, as well as gay, bisexual, and other MSM, living with and at risk for HIV in Louisiana. The five priority areas included (1) providing support for CJI populations, (2) enhancing socio-economic outcomes, (3) 
Table 2 Case study examples from mystery shopping conducted in New Orleans and Baton Rouge to document instances of housing discrimination among YBMSM, 2015-2016

Types of housing discrimination

Sexual orientation-based discrimination

Possible sexual orientation discrimination

Race-based discrimination

Possible race-based discrimination
Case study examples

New Orleans

The gay African American tester and the gay White tester both left voicemails for housing provider inquiring about the unit during which each tester mentioned his boyfriend. Neither tester received a call back. The African American and White heterosexual testers also left voicemails for the housing provider, and both received a call back within $24 \mathrm{~h}$.

During initial phone calls, the agent offered both heterosexual testers the opportunity to view the vacant $2 \mathrm{BR}$ as an example of what the $1 \mathrm{BR}$ would look like (which would be available the following month). The agent did not offer this to the gay African American tester and was quite discouraging with her comments during the initial phone call: "I do not have either one to show right now." The gay African American tester was told that he would have to put down a deposit and application before he could be put on a waiting list.

Baton Rouge

The gay African American tester was told "We do individual leasing, so in order for you two to live together, you would have to get a 2 BR and sign a lease for the 2BR, since it's individual leasing, you have to lease out per bedroom, not by apartment." Neither the White heterosexual tester who mentioned his girlfriend nor the African American heterosexual tester, who said: "When can we come in to view it?" were told about "individual" leasing.

Baton Rouge

The gay African American tester was told that there was a $\$ 40$ application fee. Both the White heterosexual tester and the African American heterosexual tester were told that there was a special and that the fee was being waived.

New Orleans

The African American heterosexual tester set up a site appointment with the agent. The tester could no longer make the appointment so he called to reschedule and the agent replied that he would call him back. The agent never called the African American heterosexual tester back. The agent told a second African American heterosexual tester via phone that the unit was already rented on Dec. 9. The White heterosexual tester confirmed on Dec. 10 that the unit was still available. The gay African American tester made it to site and was encouraged to apply. However, after the gay African American tester texted the agent his email address, the agent claimed that the email address did not work. Ultimately, the gay African American tester never received an application. The agent, who was a White gay man, emailed the White heterosexual tester an application and said over the phone after the site appointment,

"We'd like to rent the apartment to you."

The agent expressed to both African American testers that she wants a tenant who she will feel comfortable around since she lives alone in the same building as the unit for rent. She did not mention this to the White tester. The agent told the African American heterosexual tester that there was a background check but did not mention one to the White tester.

New Orleans

The agent pointed out an apartment with a confederate flag that would be available to the gay African American tester. The gay African American tester was then shown a dirty apartment which was not shown to the white tester. The agent made an encouraging comment to the white tester: "you are the kind of people we want."

The agent made comments only to African American testers about how the owner was very particular about his tenants: "He's very, very particular about who comes in here. He does credit check, job verification, and landlord history." The agent was also late to both African American testers' appointments, and for one of the appointments, did not bring keys to the unit.

The White tester received an additional follow-up phone call (13 days after the site appointment) from the agent asking if he was still interested in the apartment. Encouraging comments were also made to the White tester, including: "Glad you 
Table 2 (continued)

came by, you made my night," "In conclusion, we'd like you to live here," and "I'll get you everything you need, you tell me what you wanna do."

Baton Rouge

The White tester was told that the deposit would be waived, the application fee would be $\$ 99$, and the first months' rent would be free. Neither African American tester was told that the first month would be free; one was told that the deposit would be between $\$ 150$ and a month's rent depending on credit.

The White heterosexual tester was offered a $\$ 300$ Visa gift card to move in, while the gay and heterosexual African American testers were not offered any incentives.

improving housing outcomes, (4) reducing stigma and discrimination on HBCU campuses, and (5) creating safe spaces. Researchers and practitioners alike have called for such holistic health approaches to HIV prevention, care, and treatment where individuals living with and at risk for HIV have access to the various interventions $[12,13,15]$.

As indicated in the evaluation results, a substantial number of Black men received pre-release education. However, what is unclear is how many of those individuals likely contacted agency $\mathrm{C}$ upon release and/or were linked to HIV care or primary medical care upon release. Agency $\mathrm{C}$ is currently in the process of establishing a system to document contacts made and services provided upon release. The results from the client-centered care coordination interventions showed that almost half $(48 \%)$ of all participants living with HIV achieved viral suppression during these interventions. Additional strategies are needed to support viral suppression. Most individuals participating in the job coordination interventions needed full or part-time employment and more than $40 \%$ were either referred to employment opportunities or employed during the intervention. However, opportunities to boost referrals to employment, job training, and educational opportunities remain among this sample of participants.

The systematic audits showed that housing discrimination does occur, yet is often covert and can be difficult to detect without testing. In many cases, the discriminatory act, such as misrepresenting the availability of a unit or encouraging specific individuals, would not be apparent (or they may suspect it is so but have no way of proving it) to most applicants seeking housing. The experiences of housing discrimination uncovered by our systematic investigation were somewhat lower than expected when compared with local and national racial and sexual orientation estimates of housing discrimination [45-47]. It is plausible that housing discrimination is more prevalent than the results would suggest. One potential factor is the added complexity of the three-part tests that were used. These tests take longer to complete than matched-pair tests, so there is a higher possibility that a unit may no longer be available when second or third testers attempted to view it. This prevented additional three-part tests from being completed. This is most likely with smaller "mom-and-pop" landlords, who have fewer units available, so rates of discrimination may be higher among this group especially. Some of the testing parts were conducted over the phone and it is possible that rates of discrimination would have been higher with in-person tests. Additionally, the intersecting experiences of discrimination among YBMSM (e.g., based on race, sexual orientation, age, HIV status, and other characteristics) should be considered and provide an added dimension of complexity to these types of systematic audits $[10,21]$.

The communications campaign conducted to educate YBMSM about the signs of housing discrimination, legal rights to fair housing, and any legal recourse available to them in the event of a fair housing violation was implemented for a short duration with unknown long-term impact specifically among YBMSM.

Overall, a high number of students participated in the HBCU events. It is challenging to document the number of participants based on demographic characteristics (e.g., gender and age) for such large events. Consistent with previous research, the high number of syphilis cases identified during the HBCU HIV/STI testing events indicates a need for continued HIV/STI testing and referral to community services for students affiliated with these HBCUs [59, 77].

\section{Study Limitations and Next Steps}

In resource-restricted settings, there is often limited funding available for a comprehensive and/or more robust evaluation. Evaluation resources were particularly focused on assessing client needs and barriers to care for the three client-centered care coordination interventions (i.e., health navigation, pre/ post-release case management, social services management) and the employment intervention (i.e., utilization of job coordinators). In retrospect, the project would have benefitted from additional evaluation assessment questions associated with the implementation of the safe space and "Out of the Box" sessions such as unduplicated participation rates, changes in experiences of social isolation before and after participation, and completed HIV/STI referrals. These 
recommendations are now being implemented as part of a future community grant.

Our project would have benefitted from a pre- and postsurvey of individuals participating in the HBCU LGBTinclusive events to assess changes in knowledge and behaviors over time. Furthermore, national advocates have called for LGBT-inclusive strategies on HBCU campuses in Louisiana [78]. These efforts have articulated the need for the expansion of initial discussions to the eventual implementation of a variety of clear policies, procedures, and activities designed to promote a safe and healthy environment for all students [79]. This may include the implementation of institutional policies that prohibit bullying, harassment, and violence $[80,81]$; the establishment of clear and confidential processes for reporting and responding to LGBT-related bias incidents and hate crimes [82]; and the encouragement of student-led and organized social clubs that promote an accepting environment (e.g., gay-straight alliances) for all students $[80,83,84]$. Such programmatic efforts have been shown to address the aforementioned key factors that impede access to culturally responsive health services for Black LGBT populations $[8,85]$.

\section{Intervention Sustainability}

Many of the project interventions (i.e., health navigation, pre/ post-release case management, and job coordination in Baton Rouge) are continuing beyond the grant period. This is critical as more than 2000 non-violent prisoners were released in November 2017 as part of criminal justice reform in Louisiana [86]. The safe space and associated sessions are also continuing beyond the grant period. Integrated center partners were able to leverage an additional $\$ 130,000$ in funding to manualized the "Out of the Box" curriculum and maintain the safe space in Baton Rouge.

\section{Importance of the Local CABs and Multi-sector Partnerships}

In addition to the 13 integrated center partners, it is important to note that the New Orleans CAB served a variety of important functions within and outside the project. The CAB provided significant input in the development of the campaign focused on increasing awareness of housing discrimination impacting YBMSM. After the campaign was rolled out, the $\mathrm{CAB}$ was able to shift its focus to informing community members about housing discrimination, including making referrals to agency $\mathrm{E}$ for those who may have experienced housing discrimination.

Multi-sector partnerships are needed to reduce HIV disparities in the US and the Deep South [87, 88]. Louisiana's demonstration project represents a collaborative model to address HIV disparities among young Black men, including
YBMSM, in the Deep South. LPHI served as a trusted convener of the collaborative. It is important to note that our collaborative model was developed not only to facilitate inter-collaborative referrals, but also to provide a space for agencies to discuss strategies to enhance services within agencies, between agencies, and between cities (i.e., New Orleans and Baton Rouge). The inclusion of non-traditional partners such as civil rights organizations (i.e., agency E), legal entities (i.e., agency $\mathrm{C}$ ), and HBCUs (i.e., agencies F and G) helped contribute to the development and implementation of a broader holistic health approach to HIV prevention, care, and treatment for young Black men in Louisiana.

Acknowledgments The authors thank the participants, interventionists, $\mathrm{CAB}$ members, and integrated sector partners.

Contributors R. Brewer generated the initial concept and served as Principal Investigator of the study. All authors contributed to writing each of the manuscript sections.

Funding Information This project was supported with funds from the Office of Minority Health (Grant no. 6 CPIMP141066-03-01). R. Brewer's time was also supported by a grant from National Institute of Mental Health (NIMH) (R25MH067127) for the Visiting Professor Program at the University of California, San Francisco; Centers for Disease Control and Prevention (CDC) 5U01PS005122-03; and National Institute on Drug Abuse (NIDA) (3P30DA027828-08S1).

\section{Compliance with Ethical Standards}

Conflict of Interest Dr. Russell Brewer currently serves as advisory to Gilead's Implementation Science Group and ViiV Healthcare's Accelerate Initiative.

Ethical Approval All procedures performed in studies involving human participants were in accordance with the ethical standards of the institutional and/or national research committee and with the 1964 Helsinki declaration and its later amendments or comparable ethical standards. Institutional Review Board approval was obtained for the study.

Informed Consent Informed consent was obtained from individuals receiving the person-centered interventions.

Publisher's Note Springer Nature remains neutral with regard to jurisdictional claims in published maps and institutional affiliations.

\section{References}

1. Centers for Disease Control and Prevention. HIV among African American Gay and Bisexual men. 2017. Available at https://www. cdc.gov/hiv/pdf/group/msm/cdc-hiv-bmsm.pdf. Accessed July 26, 2017.

2. Centers for Disease Control and Prevention. HIV among African American Gay and Bisexual men. 2017. Available at https://www. cdc.gov/hiv/pdf/group/racialethnic/africanamericans/cdc-hivafricanamericans.pdf. Accessed 26 July 2017. 
3. Maulsby C, Millett G, Lindsey K, Kelley R, Johnson K, Montoya $\mathrm{D}$, et al. HIV among Black men who have sex with men (MSM) in the United States. A review of the literature. AIDS Behav. 2014;18(1):10-25. https://doi.org/10.1007/s10461-013-0476-2.

4. Millett GA, Peterson JL, Wolitski RJ. Greater risk for HIV infection of black men who have sex with men: a critical literature review. Am J Public Health. 2006;96(6):12-8.

5. Millett GA, Flores SA, Peterson JL, Bakeman R. Explaining disparities in HIV infection among black and white men who have sex with men: a metaanalysis of HIV risk behaviors. AIDS. 2007;21: 2083-91.

6. Millett GA, Peterson JL, Flores SA, Hart TA, Jeffries WL 4th, Wilson PA, et al. Comparisons of disparities and risks of HIV infection in black and other men who have sex with men in Canada, UK, and USA: a meta-analysis. Lancet. 2012;380:341-8.

7. Oster AM, Wiegand RE, Sionean C, Miles IJ, Thomas PE, Melendez-Morales L, et al. Understanding disparities in HIV infection between black and white MSM in the United States. AIDS. 2011;25:1103-12.

8. Levy ME, Wilton L, Phillips G 2nd, Glick SN, Kuo I, Brewer RA, et al. Understanding structural barriers to accessing HIV testing and prevention services among black men who have sex with men (BMSM) in the United States. AIDS Behav. 2014;18:972-96. https://doi.org/10.1007/s10461-014-0719-x.

9. Mayer K, Wang L, Koblin B, Mannheimer S, Magnus M, del Rio $\mathrm{C}$, et al. Concomitant socioeconomic, behavioral, and biological factors associated with the disproportionate HIV infection burden among Black men who have sex with men in 6 U.S. cities. Plos One. 2014;9(1):1-10. https://doi.org/10.1371/journal.pone. 0087298.

10. Nelson LE, Wilton L, Moineddin R, Zhang N, Siddiqi A, Sa T, et al. Economic, legal, and social hardships associated with HIV risk among Black men who have sex with men in six US cities. J Urban Health. 2016;93(1):170-88. https://doi.org/10.1007/ s11524-015-0020-y.

11. Garcia J, Parker C, Parker RG, Wilson PA, Philbin MM, Hirsch JS. "You're really gonna kick us out?" Sustaining safe spaces for community-based HIV prevention and control among Black men who have sex with men. Plos One. 2015. https://doi.org/10.1371/ journal.pone.0141326.

12. Halkitis PN, Wolitski RJ, Millett GA. A holistic approach to addressing HIV infection disparities in gay, bisexual, and other men who have sex with men. Am Psychol. 2013;68(4):261-73.

13. Estabrook S, Rodriguez D, Parker B, Howell TJ. HOME: A holistic approach to HIV prevention and program evaluation for young MSM of color in NYC. 2012. Available at http://www.hivforum. org/storage/documents/2012NationalSummit_Posting/b_091_ aponte.pdf. Accessed 26 July 2017.

14. Maulsby C, Millett G, Lindsey K, Kelley R, Johnson K, Montoya $\mathrm{D}$, et al. A systematic review of HIV interventions for Black men who have sex with men (MSM). BMC Public Health. 2013;13:625. https://doi.org/10.1186/1471-2458-13-625.

15. Hickson DA, Truong NL, Smith-Bankhead N, Sturdevant N, Duncan DT, Schnorr J, et al. Rationale, design, and methods of the ecological study of sexual behaviors and HIV/STIs among African American men who have sex with men in the Southeastern United States (the MARI study). PLoS One. 2015;10(12):e0143823. https://doi.org/10.1371/journal.pone. 0143823.

16. Center for American Progress. HIV/AIDS inequality: structural barriers to prevention, treatment, and care in communities of color. Why we need a holistic health approach to eliminate racial disparities in HIV/AIDS. 2012. Available at https://cdn.americanprogress. org/wp-content/uploads/issues/2012/07/pdf/hiv community of color.pdf. Accessed 26 July 2017.
17. Reif S, Safley D, McAllaster C, Wilson E, Whetten K. State of HIV in the US deep south. J Community Health. 2017;42:844-53. https://doi.org/10.1007/s10900-017-0325-8.

18. HIV.gov. National HIV/AIDS Strategy for the United States: updated to 2020. 2015. Available at: https://www.hiv.gov/federalresponse/national-hiv-aids-strategy/overview. Accessed 28 July 2017.

19. Brewer RA, Chrestman S, Mukherjee S, Mason KE, Dyer TV, Gamache P, et al. Exploring the correlates of linkage to HIV medical care among persons living with HIV (PLWH) in the Deep South: lessons learned from the Louisiana Positive Charge Initiative. AIDS Behav. 2018;22:2615-26. https://doi.org/10. 1007/s10461-018-2113-6.

20. Stopka TJ, Brinkley-Rubinstein L, Johnson K, Chan PA, Hutcheson M, Crosby R, et al. HIV clustering in Mississippi: spatial epidemiology study to inform implementation science in the Deep South. JMIR Public Health Surveill. 2018;4(2):e35. https:// doi.org/10.2196/publichealth.8773.

21. Arnold T, Brinkley-Rubenstein L, Chan PA, Perez-Brumer A, Bologna ES, Beauchamps L, et al. Social, structural, behavioral and clinical factors influencing retention in pre-exposure prophylaxis (PrEP) care in Mississippi. PLoS One. 2017;12(2):e0172354. https://doi.org/10.1371/journal.pone.0172354.

22. Centers for Disease Control and Prevention. HIV surveillance report, 2015. vol. 27. Available at https://www.cdc.gov/hiv/pdf/ library/reports/surveillance/cdc-hiv-surveillance-report-2015-vol27.pdf. Accessed 28 July 2017.

23. State of Louisiana Department of Health and Hospitals, Office of Public Health, STD/HIV Program. 2016 STD/HIV Surveillance Report. Available at http://www.ldh.la.gov/assets/oph/HIVSTD/ std/STDAnnualReports/2016 STDHIV SurveillanceReport Final.pdf. Accessed 24 Aug 2018.

24. State of Louisiana Department of Health and Hospitals, Office of Public Health, STD/HIV Program. Louisiana HIV, AIDS, and early Syphilis surveillance quarterly report. 2017. Available at http://ldh. louisiana.gov/assets/oph/HIVSTD/First_Quarter_2017HIV Syphilis_Report.pdf. Accessed 28 July 2017.

25. Office of Minority Health. HIV/AIDS initiative for minority men (AIMM). Available at https://minorityhealth.hhs.gov/omh/browse. aspx?lvl=2\&lvlid=66. Accessed 28 July 2017.

26. Chang C. Louisiana is the world's prison capital. 2016. Available at $\mathrm{http} / /$ www.nola.com/crime/index.ssf/2012/05/louisiana_is_the worlds_prison.html. Accessed 28 July 2017.

27. Sakala L. 2014. Breaking down mass incarceration in the 2010 census: state-by-state incarceration rates by race/ethnicity. https:// www.prisonpolicy.org/reports/rates.html. Accessed 28 July 2017.

28. Vera Institute of Justice. 2016. Available at https://www.vera.org/ newsroom/press-releases/new-report-sheds-light-on-who-is-innew-orleanss-jail-and-why. Accessed 28 July 2017.

29. Brewer RA, Magnus M, Kuo I, Wang L, Liu TY, Mayer KH. Exploring the relationship between incarceration and HIV among Black men who have sex with men in the United States. JAIDS. 2012;65:218-25.

30. Brewer RA, Magnus M, Kuo I, Wang L, Liu TY, Mayer KH. The high prevalence of incarceration history among Black men who have sex with men in the United States: associations and implications. Am J Public Health. 2014;104(3):448-54.

31. Schneider JA, Kozloski M, Michaels S, Skaathun B, Voisin D, Lancki N, et al. Criminal justice involvement history is associated with better HIV care continuum metrics among a population-based sample of young black MSM. AIDS. 2017;31(1):159-65.

32. Milloy MJ, Montaner J, Wood E. Incarceration of people living with HIV/AIDS: implications for treatment as prevention. Curr HIV/AIDS Rep. 2014;11(3):308-16. https://doi.org/10.1007/ s11904-014-0214-z. 
33. Harawa N, Adimora A. Incarceration, African Americans and HIV: advancing a research agenda. J Natl Med Assoc. 2008;100(1):57-62.

34. Human Rights Watch. Paying the price. Failure to deliver HIV services in Louisiana Parish Jails. 2016. Available at https://www. hrw.org/report/2016/03/29/paying-price/failure-deliver-hivservices-louisiana-parish-jails. Accessed 29 July 2017.

35. Maruschak LM. HIV in prisons, 2001-2010. 2015. Available at https://www.bjs.gov/content/pub/pdf/hivp10.pdf. Accessed 29 July 2017.

36. Louisiana Office of Public Health, STD/HIV Program. Louisiana Statewide Coordinated Statement of Need and HIV Comprehensive Plan. 2008. Available at http://new.dhh.louisiana.gov/assets/oph/ HIVSTD/hiv-aids/PLWHA_2008_Statewide_Needs_Assessment. pdf. Accessed 29 July 2017.

37. Springer SA, Pesanti E, Hodges J, Macura T, Doros G, Altice FL. Effectiveness of antiretroviral therapy among HIV infected prisoners: reincarceration and the lack of sustained benefit after release to the community. Clin Infect Dis. 2004;38:1754-60.

38. Baillargeon J, Giordano TP, Rich JD, Wu ZH, Wells K, Pollock BH, et al. Accessing antiretroviral therapy following release from prison. J Am Med Assoc. 2009;301(8):848-57.

39. Pellowski JA, Kalichman SC, Matthews KA, Adler N. A pandemic of the poor: social disadvantage and the U.S. HIV epidemic. Am Psychol. 2013;68(4):197-209.

40. Sams-Abiodun P, Rattler Jr G. Recognizing the underutilized economic potential of Black men in New Orleans. 2013. Available at http://www.gnof.org/wp-content/uploads/2015/10/Recognizingthe-Underutilized-Economic-Potential-of-Black-Men-in-NewOrleans.pdf. Accessed 4 Oct 2017.

41. Metro Morphosis. The state of Black boys and men in Baton Rouge. 2015. Available at http://urban-congress.artimization.net/ wp-content/uploads/Study.pdf. Accessed 4 Oct 2017.

42. Aidala AA, Wilson MG, Shubert V, Gogolishvili D, Globerman J, Rueda S, et al. Housing status, medical care, and health outcomes among people living with HIV/AIDS: a systematic review. Am J Public Health. 2016;106(1):e1-e23.

43. Corneil TA, Kuyper LM, Shoveller J, Hogg RS, Li K, Spittal PM, et al. Unstable housing, associated risk behaviour, and increased risk for HIV infection among injection drug users. Heath Place. 2006;12:79-85.

44. Coady MH, Latka MH, Thiede H, Golub ET, Ouellet L, Hudson $\mathrm{SM}$, et al. Housing status and associated differences in HIV risk behaviors among young injection drug users (IDUs). AIDS Behav. 2007;11(6):854-63.

45. U.S. Department of Housing and Urban Development. Housing discrimination against racial and ethnic minorities. 2012. Available at https://www.huduser.gov/portal/Publications/pdf/ HUD-514_HDS2012.pdf. Accessed 5 Oct 2017.

46. U.S. Department of Housing and Urban Development. An estimate of housing discrimination Against same-sex couples. 2013. Available at https://www.huduser.gov/portal/Publications/pdf/ Hsg_Disc_against_SameSexCpls_v3.pdf. Accessed 5 Oct 2017.

47. Greater New Orleans Fair Housing Action Center. Where opportunity knocks the doors are locked. 2014. Available at http://www. gnofairhousing.org/wp-content/uploads/2014/11/11-06-14-WhereOpp-Knocks-FINAL.pdf Accessed 5 Oct 2017.

48. Louisiana Department of Health and Hospitals, Office of Public Health. 2013. People living with HIV/AIDS needs assessment. Available at http://new.dhh.louisiana.gov/assets/oph/HIVSTD/ RFI/PLWHA_Statewide_Report_DRAFT.pdf. Accessed 5 Oct 2017.

49. Louisiana AIDS Advocacy Network. Louisiana HIV/AIDS strategy for advocacy. A field manual for change 2014. Available at http://aan.org/. Accessed 5 Oct 2017.
50. Taylor SE, Dilorio C, Stephens TT, Soett JE. A comparison of AIDS related sexual risk behaviors among African-American college students. J Natl Med Assoc. 1997;89:397-403.

51. Lewis JE, Malow RM, Ireland SJ. HIV/AIDS risk in heterosexual college students. A review of a decade of literature. J Am Coll Heal. 1997;45:147-58.

52. Johnson RL, Douglas W, Nelson A. Sexual behaviors of African American male college students and the risk of HIV infection. J Natl Med Assoc. 1992;84:864-8.

53. Campus Pride. The state of LGBTQ issues at historically Black colleges \& universities. 2012. Available at https://www. campuspride.org/resources/outreach-to-historically-black-collegesuniversities. Accessed 11 Oct 2017.

54. Ford O. This is who $\mathrm{i}$ am: a phenomenological study of the lived experiences of Black gay men with an undergraduate degree from a Historically Black College or University. Electronic thesis or dissertation. Ohio University, 2007. Available at https://etd.ohiolink. edu/!etd.send file\%3Faccession\%3Dohiou $1195566951 \%$ 26disposition\%3Dinline Accessed 5 Oct 2017.

55. National Public Radio. To be young, gifted and gay at a Black college. Interview from May 23, 2007. Available at: http://www. npr.org/templates/story/story.php?storyId=10354842. Accessed 5 Oct 2017.

56. Means D, Jaeger AJ. Black in the rainbow: "Quaring" the Black gay male student experience at Historically Black Universities. J African American Males Education. 2013;4(2):124-40.

57. Sutton MY, Gray SC, Elmore K, Gaul Z. Social determinants of HIV disparities in the southern United States and in counties with Historically Black Colleges and Universities (HBCUs), 2013-2014. PLoS One. 2017;12:e0170714. https://doi.org/10.1371/journal. prone.0170714.

58. Watson J. HBCUs challenged to address LGBT, diversity issues. 2014. Available at http://diverseeducation.com/article/65075/. Accessed 11 Oct 2017.

59. Hall NM, Peterson J, Johnson M. To test or not to test: barriers and solutions to testing African American college students for HIV at a Historically Black College/University. J Health Dispar Res Pract. 2014;7(1):2.

60. Warren-Jeanpiere L, Sutton M, Jones S. Historically Black colleges and universities' campus culture and HIV prevention attitudes and perceptions among students. J Coll Stud Dev. 2011;52L:740-8.

61. Duncan C, Miller DM, Borskey EJ, Fomby B, Dawson P, Davis L. Barriers to safer sex practices among African American college students. J Natl Med Assoc. 2002;94:944-51.

62. Garofalo R, Mustanski B, Johnson A, Emerson E. Exploring factors that underlie racial/ethnic disparities in HIV risk among young men who have sex with men. J Urban Health. 2010;87(2):318-23.

63. LeGrand S, Muessig KE, Pike EC, Baltierra N, Hightow-Weidman LB. If you build it will they come? Addressing social isolation within a technology-based HIV intervention for young Black men who have sex with men. AIDS Care. 2014;26(9):1194-200.

64. Crawford I, Allison K, Zamboni B, Soto T. The influence of dualidentity development on the psychosocial functioning of African American gay and bisexual men. J Sex Res. 2002;39(3):179-89.

65. Raymond HF, McFarland W. Racial mixing and HIV risk among men who have sex with men. AIDS Behav. 2009;13(4):630-7.

66. Kraft JM, Beeker C, Stokes JP, Peterson JL. Finding the "community" in community-level HIV/ AIDS interventions: formative research with young African American men who have sex with men. Health Educ Behav. 2000;4:430-41.

67. Glick SN, Golden MR. Persistence of racial differences in attitudes toward homosexuality in the United States. J Acquir Immune Defic Syndr. 2010;4:516-23.

68. Stokes J, Peterson J. Homophobia, self-esteem, and risk for HIV among African American men who have sex with men. AIDS Educ Prev. 1998;10(3):278-92. 
69. Ayala G, Bingham T, Kim J, Wheeler DP, Millett GA. Modeling the impact of social discrimination and financial hardship on the sexual risk of HIV among Latino and Black men who have sex with men. Am J Public Health. 2012;102(S2):S242-9.

70. Myers H, Javanbakht M, Martinez M, Obediah S. Psychosocial predictors of risky sexual behaviors in African American men: implications for prevention. AIDS Educ Prev. 2003;15(supp A):6679.

71. McKirnan DJ, Vanable PA, Ostrow DG, Hope B. Expectancies of sexual 'escape' and sexual risk among drug and alcohol-involved gay and bisexual men. J Subst Abus. 2001;1-2:137-54.

72. Harawa NT, Williams JK, Ramamurthi HC, Manago C, Avina S, Jones M. Sexual behavior, sexual identity, and substance abuse among low-income bisexual and non-gay-identifying African American men who have sex with men. Arch Sex Behav. 2008;37(5):748-762. 17.

73. Hightow-Weidman L, LeGrand S, Choi SK, Egger J, Hurt CB, Muessig JE. Exploring the HIV continuum of care among young black MSM. PLoS One. 2017;12(6):e0179688. https://doi.org/10. 1371/journal.pone.0179688.

74. Miller RL, Forney JC, Hubbard P, Camacho LM. Reinventing Mpowerment for Black men: long- term community implementation of an evidence-based program. Am J Community Psychol. 2012;49:199-214.

75. Saleh LD, Operario D, Smith CD, Arnold E, Kegeles S. "We're going to have to cut loose some of our personal beliefs": barriers and opportunities in providing HIV prevention to African American men who have sex with men and women. AIDS Educ Prev. 2011;23:521-32.

76. Creswell JW. A concise introduction to mixed methods research. Thousand Oaks: Sage Publications; 2014.

77. LeBlanc TT, Sutton MY, Thomas P, Duffus WA. HIV and STI risk for young Blacks in high prevalence areas: implications for health equity in communities hosting historically black colleges and universities (HBCUs). J Health Dispar Res Pract. 2014;7(1):1-12.

78. Lewis MW, Ericksen KS. Improving the climate for LGBTQ students at an Historically Black University. Journal of LGBT Youth. 2016;13(3):249-69.
79. Centers for Disease Control and Prevention. Lesbian, gay, bisexual, and transgender health. 2017. Available at https://www.cdc.gov/ lgbthealth/youth.htm. Accessed 7 Nov 2017.

80. Hatzenbuehler ML, Keyes KM. Inclusive anti-bullying policies reduce suicide attempts in lesbian and gay youth. J Adolesc Health. 2013;53(1 suppl):S21-6.

81. Women's Research \& Resource Center. Facilitating campus climates of pluralism, inclusivity, and progressive change at HBCUs. 2011.

82. Hatzenbuehler ML, Birkett M, Van Wagenen A, Meyer IH. Protective school climates and reduced risk for suicide ideation in sexual minority youth. Am J Pub Health. 2014;104(2):279-86.

83. Saewcy EM, Konishi C, Rose HA, Homma Y. School-based strategies to reduce suicidal ideation, suicide attempts, and discrimination among sexual minority and heterosexual adolescents in Western Canada. Int J Child, Youth Family Stud. 2014;1:89-112.

84. Heck NC, Livingston NA, Flentje A, Oost K, Stewart BT, Cochran $\mathrm{BN}$. Reducing risk for illicit drug use and prescription drug misuse: high school gay-straight alliances and lesbian, gay, bisexual, and transgender youth. Addict Behav. 2014;39:824-8.

85. Hermanstyne KA, Green HD Jr, Cook R, Tieu HV, Dyer TV, Hucks-Ortiz C, et al. Social network support and decreased risk of seroconversion in Black MSM: results from the BROTHERS (HPTN 061) study. J Acquir Immune Defic Syndr. 2018;78(2): $163-8$.

86. The Advocate. 2017. Almost 2,000 Louisiana prisoners released; what comes next? Available at http://www.theadvocate.com/baton rouge/news/crime_police/article_14364936-bf51-11e7-b43acb597328a645.html. Accessed 7 Nov 2017.

87. Andrasik MP, Chandler C, Powell B, Humes D, Wakefield S, Kripke K, et al. Bridging the divide: HIV prevention research and Black men who have sex with men. Am J Public Health. 2014;104(4):708-14.

88. Griffin JP Jr, Floyd A. How to promote effective African American partnerships for community-based HIV/AIDS planning: lessons learned from the Atlanta Regional Minority Health Network. J Health Care Poor Underserved. 2006;17(1 Suppl):44-52. 